Pacific Journal of Mathematic 


\title{
TAUBERIAN THEOREMS FOR MATRICES GENERATED BY ANALYTIC FUNCTIONS
}

\author{
John A. Fridy AND Robert E. Powell
}

\begin{abstract}
Several classes of summability matrices are determined by the coefficients of Maclaurin series of the products of certain analytic functions. These matrices include generalizations of the transforms of Lototsky, Taylor, and others. It is proved that under rather weak restrictions on the analytic functions, $x_{k}-x_{k+1}=o\left(k^{-1}\right)$ is a Tauberian condition for the resulting matrix transformations.
\end{abstract}

1. Introduction. Several classes of summability transforms are generated by products of analytic functions. The matrix $\left(a_{n, k}\right)$ of such a transform is given by

$$
\prod_{k=0}^{n} f_{k}(z)=\sum_{k=0}^{\infty} a_{n, k} z^{k},
$$

where $f_{k}(z)$ is analytic at $z=0(k=0,1,2, \cdots)$. This class of transforms includes, for example, the well-known Euler-Knopp means [6, pp. 56-60] and the Taylor transforms [6, pp. 60-64]. In addition to these two special cases, the transforms of this class for which we shall prove Tauberian theorems are the following: the Karamata transform [8, 9], the generalized Lototsky transform [4], and the $\mathscr{T}\left(r_{n}\right)$ transform [7]. We also give a Tauberian theorem for the $T\left(r_{n}\right)$ transform [5] which, although not a member of this class, is very similar to the others.

In this paper we shall state the Tauberian theorems in sequenceto-sequence form; thus, a typical Tauberian condition for a sequence $x$ is $(\Delta x)_{k}=o\left(k^{-1}\right)$, where $\Delta x$ is given by $(\Delta x)_{k}=x_{k}-x_{k+1}$. Our proofs will use recently developed techniques $[1,2]$ that are based on the concept of a "block-dominated" matrix. For each $n$, let $\left\{a_{n, k}\right\}_{k=1+\mu(n)}^{\nu(n)}$ be a block of consecutive terms of $n$th row of the matrix $A$; then $A$ is dominated by the sequence of blocks $\left\{a_{n, k}\right\}_{k=1+\mu^{\prime \prime}(n)}^{\nu^{(n)}}$ $(n=0,1, \cdots)$ provided that

$$
\liminf _{n}\left\{\left|\sum_{k=1+\mu(n)}^{\nu(n)} a_{n, k}\right|-\sum_{k \leqq \mu(n)}\left|a_{n, k}\right|-\sum_{k>\nu(n)}\left|a_{n, k}\right|\right\}>0 .
$$

Then $L_{n} \equiv \nu(n)-\mu(n)$ is called the length of the block in the $n$th row. The results from $[1,2]$ that we shall use are stated here for convenience.

Theorem A. Let $A$ be a regular matrix that is dominated by 
$\left\{a_{n, k}\right\}_{k=1+\mu(n)}^{\nu(n)}$; if $x$ is a bounded sequence that is A-summable and

$$
\max _{\mu(n)<k \leq \nu(n)}\left|(\Delta x)_{k}\right|=o\left(L_{n}^{-1}\right),
$$

then $x$ is convergent.

THEOREM B. Let $A$ be a regular matrix that is dominated by $\left\{a_{n, k}\right\}_{k=1+\mu(n)}^{(n)}$ and $a_{n, k}=0$ whenever $k>\nu(n)$; if $x$ is $A$-summable and (3) holds, then $x$ is convergent.

Lemma C. If $x$ is a sequence such that $(\Delta x)_{k}=o\left(k^{-1}\right)$ and the index sequences $\mu$ and $\nu$ are chosen so that

$$
\nu(n)=O(\mu(n)) \text { and } \lim _{n} \mu(n)=\infty,
$$

then (3) is satisfied.

Thus, for a given matrix $A$, our method will be to show that the sequences $\mu$ and $\nu$ can be chosen so that (2) and (4) are satisfied; from this we can then conclude that $(\Delta x)_{k}=o\left(L_{n}^{-1}\right)$ is a Tauberian condition for $A$.

2. Principle lemmas. Since we shall be considering regular matrices, our general task will be to show that the index sequences $\mu$ and $\nu$ can be chosen so that for each $n$,

$$
\sum_{k \leqq \mu(n)}\left|a_{n, k}\right| \leqq \rho<1 / 4
$$

and

$$
\sum_{k>\nu(n)}\left|a_{n, k}\right| \leqq \rho<1 / 4 .
$$

These inequalities, coupled with the Silverman-Toeplitz conditions for regularity, guarantee that $A$ is dominated by $\left\{a_{n, k}\right\}_{k=1+\mu(n)}^{\nu^{(n)}}(n=$ $0,1,2, \cdots)$. In order to establish (4), our method will be to show that $\mu$ and $\nu$ can be chosen so that each is given (approximately) by a linear expression in $n$. This is stated precisely using the greatest integer function in the following two lemmas.

Lemma 1. Suppose $A$ is a matrix given by (1), where each $f_{k}$ is analytic on $\{z:|z| \leqq R, R>1\}$ and there is a number $M$ such that for every $k$,

$$
\sup _{|z|=R}\left|f_{k}(z)\right| \leqq M
$$

if $\rho<1 / 4$, then there exist numbers $a$ and $b$ such that $\nu(n)=$ 
$[a n+b]+1$ and (6) holds.

Proof. Let $\Gamma=\{z:|z|=R\}$ and $g_{n}(z)=\prod_{k=0}^{n} f_{k}(z)$. Then we have

$$
\begin{aligned}
\sum_{k>\nu}\left|a_{n, k}\right| & =\sum_{k>\nu}\left|\frac{1}{2 \pi i} \int_{\Gamma} \frac{g_{n}(t)}{t^{k+1}} d t\right| \\
& \leqq \frac{1}{2 \pi} \sup _{t \in \Gamma}\left|g_{n}(t)\right| \sum_{k=\nu+1}^{\infty} \frac{1}{R^{k+1}}(2 \pi R) \\
& \leqq \frac{1}{2 \pi} M^{n+1} \frac{1}{R^{\nu+2}} \frac{1}{1-\frac{1}{R}}(2 \pi R) \\
& =\frac{1}{R-1} \frac{1}{R^{\nu}} M^{n+1} .
\end{aligned}
$$

For a given $\rho<1 / 4, \sum_{k>\nu}\left|a_{n, k}\right| \leqq \rho$ will hold provided

$$
\frac{1}{R-1} \frac{M^{n+1}}{R^{\nu}} \leqq \rho
$$

which is equivalent to

$$
R^{\nu} \geqq \frac{M^{n+1}}{\rho(R-1)}
$$

or

$$
\nu \geqq \frac{(n+1) \ln M-\ln (\rho(R-1))}{\ln R} .
$$

Hence, $a$ and $b$ can be chosen so that $\nu(n)=[a n+b]+1$ and $^{-}(6)$ holds.

Leмma 2. Suppose $A$ is a matrix given by (1), where each $f_{k}$ is analytic on $\{z:|z| \leqq R<1\}$ and there is a number $M<1$ such that for every $k$,

$$
\sup _{|z|=R}\left|f_{k}(z)\right| \leqq M
$$

if $\rho<1 / 4$, then there exist numbers $a$ and $b$ such that $a>0, \mu(n)=$ $[a n+b]$, and (5) holds. have

Proof. Let $\Gamma=\{z:|z|=R<1\}$ and $g_{n}(z)=\prod_{k=0}^{n} f_{k}(z)$. Then we

$$
\sum_{k \leq \mu}\left|a_{n, k}\right|=\sum_{k \leqq \mu}\left|\frac{1}{2 \pi i} \int_{\Gamma} \frac{g_{n}(t)}{t^{k+1}} d t\right|
$$




$$
\begin{aligned}
& \leqq \frac{1}{2 \pi} \sup _{t \in \Gamma}\left|g_{n}(t)\right| \sum_{k=0}^{\mu} \frac{1}{R^{k+1}}(2 \pi R) \\
& \leqq \frac{1}{2 \pi} M^{n+1} \frac{1}{R^{2}} \frac{\frac{1}{R^{\mu+1}}-1}{\frac{1}{R}-1}(2 \pi R) \\
& \leqq \frac{1}{1-R} M^{n+1} \frac{1}{R^{\mu+1}} .
\end{aligned}
$$

For $\rho<1 / 4, \sum_{k \leqq \mu}\left|a_{n, k}\right| \leqq \rho$ will hold provided

$$
\frac{1}{1-R} M^{n+1} \frac{1}{R^{\mu+1}} \leqq \rho,
$$

which is equivalent to

$$
R^{\mu} \geqq \frac{M^{n+1}}{\rho(1-R) R},
$$

that is,

$$
\mu \leqq \frac{(n+1) \ln M-\ln [\rho(1-R) R]}{\ln R} .
$$

Hence, $a$ and $b$ can be chosen so that $\mu(n)=[a n+b], a>0$, and (5) holds.

3. Applications. The first Tauberian theorem that we shall prove concerns the $\mathscr{T}\left(r_{n}\right)$ transform [7]. This generalization of the Taylor transform is defined by

$$
\prod_{k=0}^{n} \frac{1-r_{k}}{1-r_{k} z}=\sum_{k=0}^{\infty} a_{n, n+k} z^{k}
$$

where $a_{n, k}=0$ for $k<n$ and $\left\{r_{k}\right\}_{0}^{\infty}$ is a sequence.

Theorem 3. Suppose that $0 \leqq r_{n} \leqq \beta<1$ for $n=0,1,2, \cdots$, and $x$ is a bounded sequence that is $\mathscr{T}\left(r_{n}\right)$-summable and satisfies $(\Delta x)_{k}=o\left(k^{-1}\right)$; then $x$ is convergent.

Proof. Since $0 \leqq r_{n} \leqq \beta<1$ we have that $\mathscr{T}\left(r_{n}\right)$ is a regular matrix [7, Theorem 3.6]. Choose $\mu(n)=n$. Since $f_{k}(z)=$ $\left(1-r_{k}\right) /\left(1-r_{k} z\right)$, each $f_{k}$ is analytic on $\{z:|z| \leqq 2 /(1+\beta)\}$, and $2 /(1+\beta)>1$. For $R=2 /(1+\beta)$ we have

$$
\sup _{|z|=R}\left|f_{k}(z)\right| \leqq \frac{1-r_{k}}{\left|1-r_{k} R\right|} \leqq \frac{1}{1-\beta\left(\frac{2}{1-\beta}\right)}=\frac{1-\beta}{1+\beta} .
$$


Thus, the result follows by Lemma 1, Lemma C, and Theorem A.

The Taylor transform $T(r)$ is a special case of the $\mathscr{T}\left(r_{n}\right)$ transform, where $r_{n}=r(n=0,1,2, \cdots)$.

CoROLlary 4. If $0 \leqq r<1$ and $x$ is a bounded sequence that is $T(r)$-summable and satisfies $(\Delta x)_{k}=o\left(k^{-1}\right)$, then $x$ is convergent.

Proof. Choose $\beta=r$ in Theorem 3.

This corollary is an extension of the result contained in [1, Theorem 9].

The Karamata transform $K[a, b][8,9]$ is generated by (1) using

$$
f_{k}(z)=f(z)=\frac{a+(1-a-b) z}{1-b z} \quad k=0,1,2, \cdots .
$$

Then $K[a, b]$ is regular [8, Theorem 3] provided $-1<-b<a<1$. Each $f_{k}$ is analytic on $\{z:|z|<1 /|b|\}$ and

$$
\left|f_{k}(z)\right| \leqq \frac{|a|+|1-a-b||z|}{|1-| b|| z||}
$$

so

$$
\sup _{|z|=R}\left|f_{k}(z)\right| \leqq \frac{|a|+|1-a-b| R}{|| b|R-1|} .
$$

THEOREM 5. If $-1<-b<a<1$, and $x$ is a bounded sequence that is $K[a, b]$-summable and satisfies $(\Delta x)_{k}=o\left(k^{-1}\right)$, then $x$ is convergent.

Proof. Suppose $b=0$. Thus

$$
\sup _{|z|=R}\left|f_{k}(z)\right| \leqq|a|+|1-a| R .
$$

To apply Lemma 1 , choose $R=2$ and $M=|a|+2|1-a|$. To apply Lemma 2, choose $R=(1-|a|) / 2|1-a|$. Thus $R<1$ and

$$
\sup _{|z|=R}\left|f_{k}(z)\right| \leqq|a|+|1-a| \frac{1-|a|}{2|1-a|}=\frac{1+|a|}{2}<1 \text {. }
$$

Suppose $b \neq 0$. To apply Lemma 1 choose $R=(|b|+1) / 2|b|$. Then $1<R<1 /|b|$ and $f_{k}$ is analytic on $\{z:|z| \leqq R\}$. Moreover,

$$
\sup _{|z|=R}\left|f_{k}(z)\right| \leqq \frac{|a|+|1-a-b| \frac{|b|+1}{2|b|}}{|| b\left|\frac{|b+1|}{2|b|}-1\right|} .
$$


Now choose $M$ (of Lemma 1) to be the right-hand member of the preceding inequality. To apply Lemma 2, choose

$$
R=\frac{1-|a|}{2(|1-a-b|+|b|)} .
$$

Then $R<1$ and $f_{k}$ is analytic on $\{z:|z| \leqq R\}$. Moreover, in this case,

$$
\sup _{|z|=R}\left|f_{k}(z)\right| \leqq \frac{|a|+|1-a-b| \frac{1-|a|}{2(|1-a-b|+|b|)}}{|| a\left|\frac{1-|a|}{2(|1-a-b|+|b|)}-1\right|}<1 .
$$

Therefore the result follows by Lemma 1, Lemma 2, Lemma $\mathrm{C}$, and Theorem A.

The generalized Lototsky transform $\left[L, d_{n}\right]$ [4] is generated by (1) using $f_{0}(z) \equiv 1$ and

$$
f_{k}(z)=\frac{z+d_{k}}{1+d_{k}}, \quad k=1,2, \cdots .
$$

Then $\left[L, d_{n}\right]$ is a lower triangular matrix and, for $h_{k}=\left(1+d_{k}\right)^{-1}$ where $0<\alpha \leqq h_{k} \leqq 1$, the transform is regular [4, Theorems 3.1 and 3.2]. Also, the generating functions become $f_{k}(z)=1-h_{k}+h_{k} z$ for $k \geqq 1$.

THEOREM 6. If $0<\alpha \leqq\left(1+d_{k}\right)^{-1} \leqq 1$, and the sequence $x$ is $\left[L, d_{n}\right]$-summable and satisfies $(\Delta x)_{k}=o\left(k^{-1}\right)$, then $x$ is convergent.

Proof. Let $\nu(n)=n$, and note that each $f_{k}$ is an entire function. Choose $R=\alpha / 2<1$. Substituting $h_{k}=\left(1+d_{k}\right)^{-1}$, we have

$$
\left|f_{k}(z)\right|=\left|1-h_{k}+h_{k} z\right| \leqq\left|1-h_{k}\right|+\left|h_{k}\right||z| \text {. }
$$

Hence,

$$
\sup _{|z|=R}\left|f_{k}(z)\right| \leqq 1-\alpha+(1) \frac{\alpha}{2}<1 .
$$

The result now follows from Lemma 2, Lemma $\mathrm{C}$, and Theorem $\mathrm{B}$.

In the special case where $h_{k} \equiv r$, the $\left[L, d_{n}\right]$-transform becomes the Euler-Knopp transform $E(r)$. Thus, the result in Theorem 6 holds for $E(r)$ when $0<r \leqq 1$. This is a weaker result, however, than the Hardy-Littlewood result [3] for $E(r)$ which uses the Tauberian condition $(\Delta x)_{k}=O\left(k^{-1 / 2}\right)$. 
The $T\left(r_{n}\right)$-transform [5] is defined by $a_{n, k}=0$ for $k<n$ and

$$
\left[f_{n}(z)\right]^{n}=\sum_{k=0}^{\infty} a_{n, n+k} z^{k}
$$

where $f_{n}(z)=\left(1-r_{n}\right) /\left(1-r_{n} z\right)$. This form is slightly different than (1), but with minor modifications in Lemmas 1 and 2 , the following Tauberian theorem can be proved for the $T\left(r_{n}\right)$-transform.

THEOREM 7. If $0 \leqq r_{n} \leqq \beta<1$, and $x$ is a bounded sequence that is $T\left(r_{n}\right)$-summable and satisfies $(\Delta x)_{k}=o\left(k^{-1}\right)$, then $x$ is convergent.

\section{REFERENCES}

1. J. A. Fridy, Tauberian theorems via block dominated matrices, Pacific J. Math., 81 (1979), 81-91.

2. - An addendum to Tauberian theorems via block dominated matrices, submitted for publication.

3. G. H. Hardy and J. E. Littlewood, Theorems concerning summability of series by Borel's exponential method, Rend. Circ. Palermo, 41 (1916), 36-53.

4. A. Jakimovski, A generalization of the Lototsky method, Michigan Math. J., 6 (1959), 277-290.

5. J. P. King, An extension of the Taylor summability transform, Proc. Amer. Math. Soc., 16 (1965), 25-29.

6. R. E. Powell and S. M. Shah, Summability Theory and Applications, Van Nostrand. Reinhold, London, 1973.

7. R. E. Powell, The $\mathscr{T}\left(r_{n}\right)$ summability transform, J. d'Analyse Mathematique, XX (1967), 289-304.

8. W. T. Sledd, Regularity methods for Karamata matrices, J. London Math. Soc., 38 (1963), 105-107.

9. J. Sonnenschein, Sur les series divergentes, Bull Acad. Royale de Belgique, 35 (1949), 594-601.

Received June 14, 1979.

Kent State University

Kent, OH 44242 



\section{PACIFIC JOURNAL OF MATHEMATICS}

\section{EDITORS}

DONALD BABBITT (Managing Editor)

University of Galifornia

Los Angeles, California 90024

Hugo RossI

University of Utah

Salt Lake City, UT 84112

C. C. MOORE AND ANDREW OGG

University of California

Berkeley, CA 94720
J. DUGUNDJI

Department of Mathematics University of Southern California Los Angeles, California 90007

R. Finn AND J. Milgram Stanford University Stanford, California 94305

\section{ASSOCIATE EDITORS}

R. ARENS

E. F. BECKENBACH

B. H. NEUManN

F. WOLF

K. YOSHIDA

\section{SUPPORTING INSTITUTIONS}

UNIVERSITY OF ARIZONA

UNIVERSITY OF BRITISH COLUMBIA CALIFORNIA INSTITUTE OF TECHNOLOGY

UNIVERSITY OF CALIFORNIA

MONTANA STATE UNIVERSITY

UNIVERSITY OF NEVADA, RENO

NEW MEXICO STATE UNIVERSITY

OREGON STATE UNIVERSITY
UNIVERSITY OF OREGON

UNIVERSITY OF SOUTHERN CALIFONIA

STANFORD UNIVERSITY

UNIVERSITY OF HAWAII

UNIVERSITY OF TOKYO

UNIVERSITY OF UTAH

WASHINGTON STATE UNIVERSITY

UNIVERSITY OF WASHINGTON 


\section{Pacific Journal of Mathematics}

\section{Vol. 92, No. $1 \quad$ January, 1981}

Michael E. Adams and J. Sichler, Lattices with unique complementation . ....1

Walter Allegretto, Positive solutions and spectral properties of second order

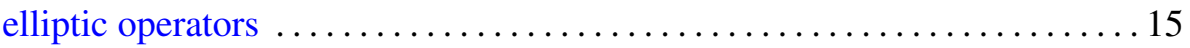

Philip J. Boland and Sean Dineen, Holomorphy on spaces of distribution . . 27

Duncan Alan Buell, Philip A. Leonard and Kenneth S. Williams, Note on

the quadratic character of a quadratic unit $\ldots \ldots \ldots \ldots \ldots \ldots \ldots \ldots \ldots$

Herbert Busemann and Bhalchandra B. Phadke, Two theorems on

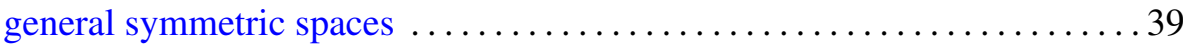

Emeric Deutsch, Bounds for the Perron root of a nonnegative irreducible

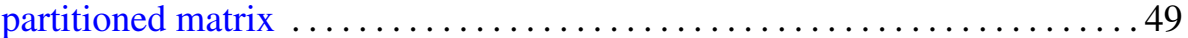

Charles F. Dunkl, A difference equation and Hahn polynomials in two

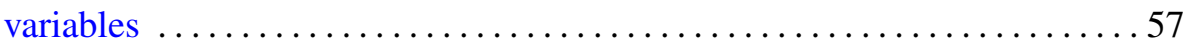

Gustave Adam Efroymson, The Riemann mapping theorem for planar Nash

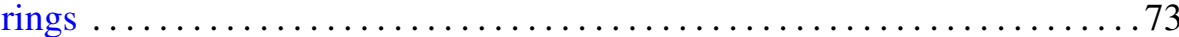

John Albert Fridy and Robert Ellis Powell, Tauberian theorems for matrices generated by analytic functions

Denton Elwood Hewgill, John Hamilton Reeder and Marvin Shinbrot,

Some exact solutions of the nonlinear problem of water waves .......887

Bessie Hershberger Kirkwood and Bernard Robert McDonald, The

symplectic group over a ring with one in its stable range

Esther Portnoy, Transitive groups of isometries on $H^{n}$

Jerry Ridenhour, On the sign of Green's functions for multipoint boundary

value problems

Nina M. Roy, An $M$-ideal characterization of $G$-spaces

Edward Barry Saff and Richard Steven Varga, On incomplete

polynomials. II

Takeyoshi Satō, The equations $\Delta u=P u(P \geqq 0)$ on Riemann surfaces and

isomorphisms between relative Hardy spaces

James Henry Schmerl, Correction to: "Peano models with many generic classes"

Charles Madison Stanton, On the closed ideals in $A(W)$

Viakalathur Shankar Sunder, Unitary equivalence to integral operators

Pavel G. Todorov, New explicit formulas for the $n$th derivative of composite functions

James Li-Ming Wang, Approximation by rational modules on boundary sets

Kenneth S. Williams, The class number of $Q(\sqrt{p})$ modulo 4 , for $p \equiv 5$

$(\bmod 8)$ a prime 